OPEN ACCESS

Edited by:

John R. Hurst,

University College London, United Kingdom

Reviewed by:

David Andrew Fulcher, Australian National University, Australia

Vanessa L. Bryant,

Walter and Eliza Hall Institute of

Medical Research, Australia

*Correspondence:

Charlotte Cunningham-Rundles charlote.cunningham-rundles@ mssm.edu

Specialty section:

This article was submitted to

Primary Immunodeficiencies,

a section of the journal

Frontiers in Immunology

Received: 14 September 2020 Accepted: 15 February 2021

Published: 11 March 2021

Citation:

Lopes JP, Ho H-e and

Cunningham-Rundles $C$ (2021) Interstitial Lung Disease in Common

Variable Immunodeficiency.

Front. Immunol. 12:605945

doi: 10.3389/fimmu.2021.605945

\section{Interstitial Lung Disease in Common Variable Immunodeficiency}

\author{
Joao Pedro Lopes ${ }^{1,2}, \mathrm{Hsi}$-en $\mathrm{Ho}^{2}$ and Charlotte Cunningham-Rundles ${ }^{2 *}$ \\ ${ }^{1}$ Division of Allergy, Immunology and Rheumatology, Department of Pediatrics, UH University Hospitals Rainbow Babies and \\ Children, Cleveland, $\mathrm{OH}$, United States, ${ }^{2}$ Division of Clinical Immunology, Department of Medicine, Icahn School of Medicine \\ at Mount Sinai, New York, NY, United States
}

Interstitial lung disease (ILD) is a common complication in patients with common variable immunodeficiency (CVID) and often associated with other features, such as bronchiectasis and autoimmunity. As the ILD term encompasses different acute and chronic pulmonary conditions, the diagnosis is commonly made based on imaging features; histopathology is less frequently available. From a cohort of 637 patients with CVID followed at our center over 4 decades, we reviewed the data for 46 subjects (30 females, 16 males) who had lung biopsies with proven ILD. They had a median age at CVID diagnosis of 26 years old, with a median IgG level at diagnosis of 285.0 $\mathrm{mg} / \mathrm{dL}$ with average isotype switched memory B cells of $0.5 \%$. Lung biopsy pathology revealed granulomas in 25 patients (54.4\%), lymphoid interstitial pneumonia in 13 patients (28.3\%), lymphoid hyperplasia not otherwise specified in 7 patients (15.2\%), cryptogenic organizing pneumonia in 7 patients (15.2\%), follicular bronchitis in 4 patients $(8.7 \%)$, and predominance of pulmonary fibrosis in 4 patients (8.7\%). Autoimmune manifestations were common and were present in $28(60.9 \%)$ patients. Nine patients (19.6\%) died, with a median age at death of 49-years-old. Lung transplant was done in 3 of these patients (6.5\%) who are no longer alive. These analyses reveal the high burden of this complication, with almost one-fifth of the group deceased in this period. Further understanding of the causes of the development and progression of ILD in CVID patients is required to define the best management for this patient population.

Keywords: common variable immune deficiency (CVID), interstitial lung disease (ILD), autoimmunity, lung transplant, cytopenia, malignancy, lymphoma

\section{INTRODUCTION}

Common variable immunodeficiency (CVID) is the most prevalent form of clinically-recognized primary immunodeficiency, characterized by low serum IgG levels, usually a low IgA, and often a low IgM, reduced or absent antibody responses to disease or immunizations. This defect leads to recurrent infections, with particular emphasis on the sinorespiratory tract (1-6). CVID is also commonly associated with inflammatory complications, leading to chronic lung disease, generalized lymphoid hypertrophy, splenomegaly, gastrointestinal disease, and cytopenias, amongst other inflammatory manifestations (7-11). Interstitial lung disease (ILD) is a term that encompasses a group of different acute and chronic pulmonary conditions with common clinical and physiological characteristics. This condition is a common complication in patients with CVID. The diagnosis of ILD is commonly made based on clinical presentation and includes 
characteristic imaging features. For those in whom a biopsy was performed, histology provides further confirmation of the diagnosis, along with the individual pathologic features (12-14).

Chronic lung disease, including ILD, is often associated with other inflammatory features, such as lymphoid hyperplasia and autoimmunity. When present, the lung damage is associated with shortened survival; this has been noted as the leading cause of death in some CVID cohorts (5, 7, 9, 15-22). Previous publications have addressed the frequency of clinically diagnosed ILD in CVID, noted in the 10-20\% range (15$18,23)$. Bates et al. on a cohort of 69 CVID patients showed reduced survival for ILD vs. non-ILD patients (17). In this study, the ILD diagnosis was associated with a propensity for $\mathrm{T}$ cell lymphopenia, splenomegaly, and restrictive pulmonary physiology (17). Relative lymphopenia was also noted in data on a cohort from the USIDNET (United States Immunodeficiency Network) Registry; here, Kellner et al. analyzed data from 1,518 CVID patients, of whom 138 patients (9.1\%) had an ILD diagnosis. These patients had lower CD3, CD4, and CD8 T cell counts than patients without ILD, suggesting an increased risk of complications related to these abnormalities (18).

While the pathogenesis of ILD in a significant number of CVID patients remains unclear, genetic defects, and $\mathrm{T}$ cell and $\mathrm{B}$ cell dysregulation have been associated with progression. As suggested by Weinberger et al. based on comparing patients with X-linked agammaglobulinemia (XLA) to CVID patients in the USIDNET Registry, lack of antibody alone would not appear to be the leading cause of ILD, as a higher frequency of ILD, as well as of respiratory infections and asthma, was described in CVID when compared to patients with XLA (24).

In the absence of a consensus in terms of the best therapeutic approach for CVID patients with ILD (25), several therapeutic options have been discussed with an attempt to control, even if not to reverse, the progression of ILD in CVID patients (20). These include rituximab, corticosteroids, and a number of other immunosuppressive agents (26-28).

Here we review data on a group of patients in our New York CVID cohort who had biopsy-proven ILD, examining their clinical, laboratory, radiologic, histopathological, and functional data. We also aimed to review the existing data on the spectrum of ILD in CVID, to put our findings in perspective of the joint efforts by other groups to better understand this presentation's pathophysiology and potential avenues for better prevention and treatment in the near future.

\section{MATERIALS AND METHODS}

\section{Patients}

A cohort of 637 subjects with CVID (337 females and 285 males) were seen at Mount Sinai Medical Center from 1986 through the present. The first part of the cohort was previously seen at Memorial Sloan-Kettering Cancer Center (1974-1986); subsequently, these subjects were seen at Mount Sinai Medical Center. The diagnosis of CVID was made by standard criteria, including reduced serum IgG, IgA, and/or IgM, by at least 2 SDs below the mean for age, with poor or absent antibody production to both protein and carbohydrate vaccines and exclusion of other causes of hypogammaglobulinemia. Subjects under age 4 years without continued follow-up and subjects with lymphoid cancer diagnosed within 2 years after the diagnosis of CVID were excluded. For the 46 patients with biopsy-proven ILD, medical, radiologic immunologic, and pathology data were reviewed for this report.

\section{Immunologic Parameters}

Enumeration of $\mathrm{T}$ and $\mathrm{B}$ cells, CD4, and CD8 T cells, and $\mathrm{IgM}^{-} \mathrm{IgD}^{-} \mathrm{CD}_{27}^{+}$isotype switched memory $\mathrm{B}$ cells as a proportion of total $\mathrm{B}$ cells were determined.

\section{Data}

Data was abstracted in Microsoft Excel and analyzed in IBM SPSS Statistics. All studies were undertaken with the consent of the Mount Sinai Medical Center Institutional Review Board.

\section{RESULTS}

\section{Demographics and Immune Phenotypes}

Forty-six patients with biopsy-confirmed ILD and for whom pathology reports were available, included 30 females and 16 males. Two patients were African American; the rest were Caucasian. The age at CVID diagnosis was 26 years (range 1.066.0 years old), with lung symptoms appearing, as noted in the chart, at a median age of 29 years (range 1.0-59.0 years old). Immunoglobulin replacement was started later, at a median age of 32.5 years (Table 1). Baseline immunoglobulins, IgG, IgA, and IgM, are noted in Table 2, with the values presented in the Table for this group of 46 patients with CVID and ILD, similar to 500 other CVID subjects in this cohort with no known ILD $(\operatorname{IgG}=246+/-221 \mathrm{mg} / \mathrm{dL} ; \mathrm{IgA}=7.0+/-30.4 \mathrm{mg} / \mathrm{dL}$, and $\mathrm{IgM}=20+/-166.4 \mathrm{mg} / \mathrm{dL}$ ) (Mann-Whitney test). Absolute CD3, CD4, CD8 T cells, and CD19 B lymphocyte numbers were overall within normal limits but with wide variation. The percent of isotype switched memory B cells were low, as characteristic of CVID subjects (Table 2).

\section{Pathology}

Lung biopsy pathology revealed granulomatous infiltrates in 25 of the 46 patients (54.3\%), lymphoid interstitial pneumonia in 13 (28.3\%), lymphoid hyperplasia not otherwise specified in $7(15.2 \%)$, cryptogenic organizing pneumonia in $7(15.2 \%)$, follicular bronchitis in $4(8.7 \%)$, and predominance of pulmonary fibrosis in 4 patients (8.7\%). Combinations of these pathologic findings were found in several subjects (Table 3). Figure 1 contains the lung biopsy of one of the ILD/CVID patients in this group, demonstrating the presence of a granulomatous lesion

TABLE 1 | Demographic information of CVID patients with ILD included in the study.

Age (46 subjects, 30 females, 16 males)

CVID diagnosis (years-old; median, SD)

$26.0(17.8)$

Onset lung symptoms (years-old, median, SD)

$29.8(16.5)$

Ig replacement (years-old, median, SD) 
TABLE 2 | Immunologic laboratory data of CVID patients with ILD.

\begin{tabular}{|c|c|}
\hline Immunoglobulins & (Median +/- SD) \\
\hline $\begin{array}{l}\text { Baseline lgG } \\
\text { (normal } 700-1,600 \text { mg/dL) }\end{array}$ & $\mathbf{2 8 5 . 0} \mathrm{mg} / \mathrm{dL}(232.0)$ \\
\hline $\begin{array}{l}\text { Baseline lgA } \\
\text { (normal 90-386 mg/dL) }\end{array}$ & 6.5 mg/dL (11.2) \\
\hline $\begin{array}{l}\text { Baseline lgM } \\
\text { (normal 20-172 mg/dL) }\end{array}$ & 25.5 mg/dL (59.0) \\
\hline $\begin{array}{l}\text { Lymphocytes } \\
\text { (average count, SD) }\end{array}$ & (median +/- SD) \\
\hline $\begin{array}{l}\text { ABS CD3 T cells } \\
\text { (normal } 575-2,237 / \mu \mathrm{L} \text { ) }\end{array}$ & $\begin{array}{l}898.0(714.8) \\
\text { range } 278-4232\end{array}$ \\
\hline $\begin{array}{l}\text { ABS CD4 T cells } \\
\text { (normal } 325-1,472 / \mu \mathrm{L} \text { ) }\end{array}$ & $\begin{array}{l}555.0(476.1) \\
\text { range 203-2828 }\end{array}$ \\
\hline $\begin{array}{l}\text { ABS CD8 T cells } \\
\text { (normal 109-897/ } \mu \mathrm{L} \text { ) }\end{array}$ & $\begin{array}{l}366.0(287.6) \\
\text { range 62-1404 }\end{array}$ \\
\hline $\begin{array}{l}\text { ABS B cells } \\
\text { (normal 12-645/mm3) }\end{array}$ & $\begin{array}{l}83.4(128.7) \\
\text { range } 0-512\end{array}$ \\
\hline $\begin{array}{l}\text { Isotype switched CD27+B cells } \\
\text { (\% of B cells] } \\
\text { (normal 10-22.2\%) }\end{array}$ & $\begin{array}{l}\mathbf{0 . 5} \%(1.4 \%) \\
\text { range } 0-5.8 \%\end{array}$ \\
\hline
\end{tabular}

Values bold when outside the normal reference range.

TABLE 3 | Lung pathology encountered in the CVID patients with ILD.

\begin{tabular}{lcc}
\hline & Number & Percent \\
\hline Granulomas & 17 & 37 \\
LIP & 7 & 15.2 \\
COP & 4 & 8.7 \\
Fibrosis & 3 & 6.5 \\
LIP, granulomas & 3 & 6.5 \\
Lymphoid hyperplasia & 3 & 6.5 \\
LIP, follicular bronchiolitis & 2 & 4.3 \\
COP, fibrosis & 1 & 2.2 \\
COP, granulomas & 1 & 2.2 \\
Follicular bronchiolitis, lymphoid hyperplasia, granulomas & 1 & 2.2 \\
LIP, COP, granulomas & 1 & 2.2 \\
Lymphoid hyperplasia & 1 & 2.2 \\
Lymphoid hyperplasia, granulomas & 1 & 2.2 \\
Lymphoid hyperplasia, granulomas, follicular bronchiolitis & 1 & 2.2 \\
Total & 46 & 100 \\
\hline
\end{tabular}

COP, Cryptogenic organizing pneumonia; LIP, lymphocytic interstitial pneumonia.

with lymphocytic infiltration. Bronchiectasis was concomitantly described in $8(17.4 \%)$ patients.

\section{Lung Functions}

Results available for 28 patients $(60.9 \%)$ revealed the group to have an average FEV1/FVC ratio of 0.85 (standard deviation of 0.11 ; normal ratio above 0.75 ), with an average FEV1 of 0.71 (standard deviation of 0.17 ; normal FEV1 above 0.80 ) and FVC of 0.72 (standard deviation of 0.18 ; normal FVC above 0.80 ). The average TLC was 0.78 (standard deviation of 0.14 ; normal TLC above 0.80 ) and the average DLCO was $60.8 \%$ of predicted (standard deviation $22.3 \%$, range 16.0 to $109.0 \%$; normal DLCO above $75.0 \%$ of predicted).

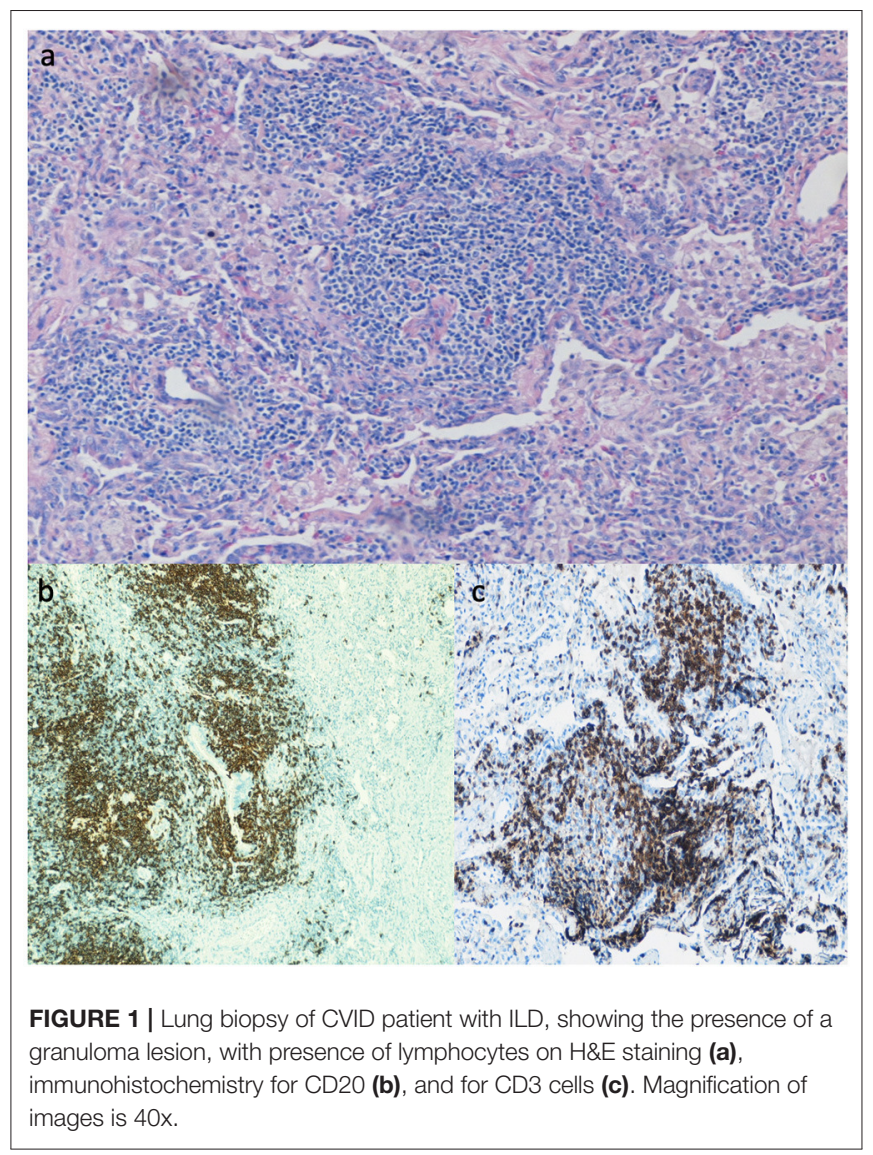

\section{Radiologic Studies}

Chest $\mathrm{x}$-rays were available for 15 patients (32.6\%), describing the presence of nodular opacities in 12 patients $(80.0 \%)$ reticular infiltrates in 6 patients (40.0\%), and fibrosis in 2 patients (13.3\%). Computerized tomography scans of the chest were available for 32 patients $(69.6 \%)$. Findings were notable for the presence of nodules in 30 patients (93.8\%), mediastinal lymphadenopathy in 21 patients $(65.6 \%)$, ground-glass appearance in 12 patients (37.5\%), diffuse consolidation in 4 patients (12.5\%), granulomas in 2 patients $(6.3 \%)$, and fibrosis in 1 patient (3.1\%). Examples of radiologic findings are shown in Figure 2 (chest x-ray) and Figure 3 (chest CT scan).

\section{Clinical Features}

Autoimmune manifestations other than in the lung were present in $28(60.9 \%)$ patients, with 12 of those patients $(26.1 \%)$ having more than one autoimmune manifestation. Cytopenias were a common manifestation: immune thrombocytopenic purpura (ITP) in 18 patients $(39.1 \%)$, autoimmune hemolytic anemia (AIHA) in 9 patients $(19.6 \%)$, autoimmune neutropenia in 6 patients $(13.0 \%)$, pancytopenia in 3 patients $(6.5 \%)$, and red blood cell aplasia in 2 patients (4.3\%). Many had more than one of these conditions, most commonly, AIHA and ITP. Other conditions included uveitis, severe aphthous ulcers, primary biliary cholangitis, and rheumatoid arthritis in one patient each. Twenty nine patients $(63.0 \%)$ were observed to have lymphadenopathy, and the same number to have splenomegaly. Splenectomy had been done in 10 of these patients $(21.7 \%)$. 


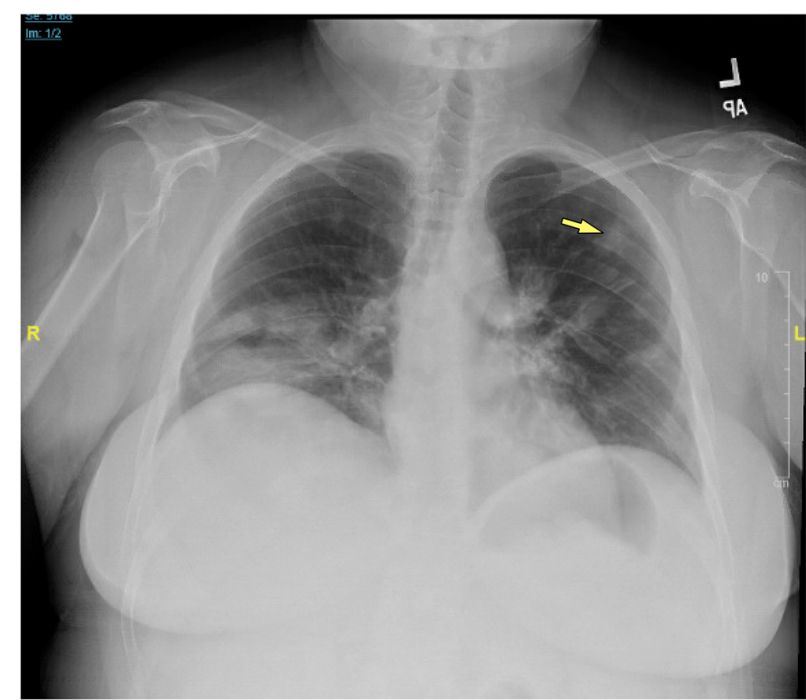

FIGURE 2 | Chest $x$-ray of CVID/ILD patient demonstrating presence of $1.6 \mathrm{~cm}$ lesion in the left upper lobe (yellow arrow), as well as patchy densities in the mid to lower lung fields.

Nodular regenerative hyperplasia of the liver was noted in 7 patients $(15.2 \%)$. Five of these patients (10.9\%) developed a malignancy, with 4 (8.7\%) developing a lymphoma. One other patient had ovarian cancer.

Unusual infections were identified in several of these patients: 5 patients $(10.9 \%)$ had herpes zoster (caused by the varicella zoster virus), 1 patient (2.2\%) had atypical mycobacteria lung infection, 1 patient $(2.2 \%)$ had measles encephalitis, 1 patient (2.2\%) had metapneumovirus infection, and 1 patient $(2.2 \%)$ had Pseudomonas otitis complicated by Pseudomonas bacteremia.

\section{Genetics}

A gene mutation associated with or contributing to the patient's CVID phenotype was identified in 10 of the 31 subjects available for testing by whole-exome sequencing (32.3\%); 3 patients (9.7\%) had a CTLA4 mutation, 2 patients $(6.5 \%)$ had an NFKB1 mutation, 2 patients $(6.5 \%)$ had either one or two TACI (TNFRSF13B) mutations, and 1 each had a STAT3 mutation, KMT2D mutation, or a PIK3CD mutation (3.2\%).

\section{Treatment and Outcomes}

Treatment modalities used in these subjects are outlined in Table 4. Seven patients (15.2\%) required chronic oxygen supplementation, and 5 patients (10.9\%) were diagnosed with pulmonary hypertension. Lung transplant had been done in 3 of the patients described here (6.5\%); none are currently surviving (Table 5). Overall, 9 of these patients (19.6\%) have died, with a median age of death of 49.0 years-old (range 27.0-70.0 years-old, standard deviation of 15.1 years).

\section{DISCUSSION}

We describe 46 patients with biopsy-characterized ILD in our cohort of 637 CVID patients, $7.2 \%$ of the cohort. As recently published, based on both radiologic studies and pathology, the

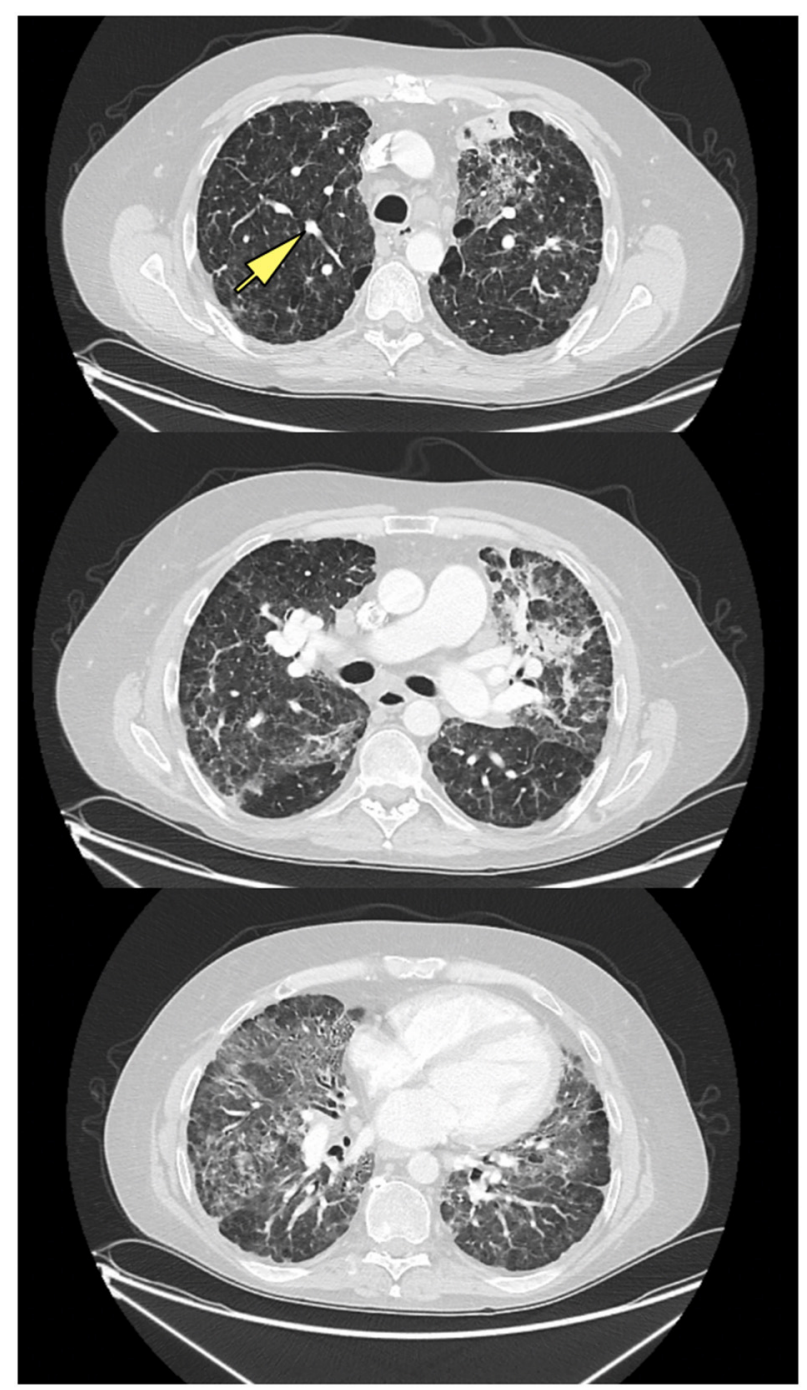

FIGURE 3 | CT scan of ILD/CVID patient, with upper, middle, and lower lung zones, demonstrating mid to lower lung zone predominant ground glass opacities, within a bronchovascular distribution, with associated volume loss, with left upper lobe consolidation in association with air bronchograms, likely pneumonia, new solid nodular opacity $(12 \times 7 \mathrm{~mm}$ ) (yellow arrow) in the right upper lobe, as well as bilateral hilar lymphadenopathy.

overall frequency of ILD in our CVID cohort is $10.4 \%$ (15), similar to other reports in which the incidence ranges from 10 to $20 \%$ in CVID $(16,18,23,29)$. In this report, we focus on the subjects for whom a biopsy had been done to provide further pathology.

A study by Patel et al. on data from the Oxford Primary Immune Deficiencies Database evaluated lung biopsies from 16 CVID patients, recognizing the presence of lymphocytic infiltrations as the most common pattern. In the Oxford report, 5 of these patients were also evaluated with immuno-markers, showing $\mathrm{T}$ cell infiltrates in 4 patients and $\mathrm{B}$ cell infiltrates in one other individual (30). In contrast, analysis of the lung biopsy results in our group demonstrated granulomatous infiltration in more than half of our patients. The commonly used term of granulomatous-lymphocytic interstitial lung disease (GLILD) 
TABLE 4 | Treatment modalities used in the CVID patients with ILD in the study.

\begin{tabular}{ll}
\hline Corticosteroids & 23 patients $(50.0 \%)$ \\
Rituximab & 16 patients $(34.8 \%)$ \\
Mycophenolate mofetil & 5 patients $(10.9 \%)$ \\
Azathioprine & 4 patients $(8.7 \%)$ \\
Mercaptopurine & 2 patients $(4.3 \%)$ \\
Hydroxychloroquine & 2 patients $(4.3 \%)$ \\
Abatacept & 1 patient $(2.2 \%)$ \\
Sirolimus & 1 patient $(2.2 \%)$ \\
Cyclosporine & 1 patient $(2.2 \%)$ \\
\hline
\end{tabular}

can be applied to these subjects. Lymphoid infiltrations were the second most prevalent condition, found in 20 patients.

Almost all patients had a description of numerous lung nodules from the radiologic perspective, and nearly twothirds had mediastinal lymphadenopathy. More than one third had areas with ground-glass appearance. Only 2 patients had "granulomas" suggested on their CT report. As more than half of the patients had granulomas present in biopsies, it is clear that, from the CT perspective, this form of pathology would not be clarified by radiologic observations. As previously suggested (31), it is important not only to recognize specific CT patterns of ILD but also early lung abnormalities at a subclinical level. Not surprisingly, patients had impaired lung functions with reduced FEV1, FVC, TLC, and DLCO, all in line with a restrictive disease pattern previously described in similar cohorts (17).

In previous studies, B cell dysregulation has been associated with progression of ILD. Maglione et al. analyzed CVID patients with ILD treated with rituximab, noting that recurrence of lung disease was associated with an increase of $B$ cell-activating factor (BAFF) in the peripheral blood; this could potentially lead to the $\mathrm{B}$ cell hyperplasia in the lung, with the development of germinal centers as one driver of lung damage in these patients (32). In the same paper, progression of ILD, as well as ILD recurrence post-rituximab, were also seen to be associated with increasingly elevated serum IgM, potentially a reflection of the increasing hyperplasia of local pulmonary B cell follicles (32). However, for the 46 biopsied subjects examined here, serum IgM was not different from 500 other subjects in this cohort without confirmed ILD.

In previous ILD studies, patients have commonly been noted to have many additional inflammatory complications (33). In our group, splenomegaly and lymphadenopathy were present in nearly two-thirds of the patients, and more than half had had cytopenias (mostly ITP, but also AIHA or neutropenia). In one cohort of 105 adult CVID patients, more patients had splenomegaly $(74.0 \%)$ and lymphadenopathy $(63 \%)$ than nonILD patients (16). Maglione et al. also reviewed CT imaging from CVID patients with pulmonary disease; here, while the presence of bronchiectasis was associated with a higher number of infections, imaging patterns of ILD were more frequently associated with autoimmunity and lymphoproliferation (21). The high frequency of splenomegaly and the history of cytopenias were also highlighted as potential predictors of granulomatous lymphocytic interstitial lung disease (GLILD) by Hartono et al. in a 2017 study (33). In our cohort, splenectomy had been performed in more than one-fifth of these patients for one or
TABLE 5 | Lung transplant characteristics in this cohort.

\begin{tabular}{llll}
\hline & Patient 1 & Patient 2 & Patient 3 \\
\hline $\begin{array}{l}\text { Year born } \\
\text { Lung pathology }\end{array}$ & $\begin{array}{l}\text { 1959 } \\
\text { Chronic } \\
\text { obstructive } \\
\text { pulmonary disease granuloma }\end{array}$ & $\begin{array}{l}\text { Pulmonary fibrosis } \\
\text { predominates with }\end{array}$ & $\begin{array}{l}1949 \\
\text { ILD (granuloma } \\
\text { and lymphoid } \\
\text { infiltrate), } \\
\text { bronchiectasis }\end{array}$ \\
$\begin{array}{l}\text { CVID-associated } \\
\text { comorbidities }\end{array}$ & $\begin{array}{l}\text { Enteropathy } \\
\begin{array}{l}\text { Transplant } \\
\text { procedure }\end{array}\end{array}$ & Liver disease & None \\
$\begin{array}{l}\text { Year of transplant } \\
\text { procedure (age) } \\
\text { Outcome }\end{array}$ & $\begin{array}{l}\text { 1983 (age 34) } \\
\text { Died of chronic } \\
\text { rejection after 5 }\end{array}$ & $\begin{array}{l}\text { 1997 (age 34) } \\
\text { Operative } \\
\text { complications, died of } \\
\text { hyperacute rejection } \\
\text { within a week }\end{array}$ & $\begin{array}{l}\text { Lejection after 8 } 8 \\
\text { months; CMV } \\
\text { infection }\end{array}$ \\
\hline
\end{tabular}

more of these cytopenias and/or hypersplenism. Noteworthy as well is that nodular regenerative hyperplasia of the liver, another inflammatory condition of unclear etiology, was documented in 7 of these patients (15.2\%).

CVID patients are also known to have increased malignancy rates, particularly lymphoma, described with a rate of $1.6-8.2 \%$ of CVID patients, depending on the cohort $(9,19,34)$. In this group, the rate was $8.7 \%$, a remarkable reminder of the higher risk for lymphoma in this particular patient group and the importance of appropriate surveillance.

As for treatment, rituximab, a monoclonal antibody targeting CD20, with the goal of B cell depletion, has been successfully used in this patient population, as monotherapy or in combination with other immune suppressants $(26,32,35,36)$. Chase et al. examined combination therapy with rituximab and azathioprine in 7 patients, noting improvement in both pulmonary function and CT abnormalities, without significant treatment side effects (27). Corticosteroids have been one of the mainstays of ILD treatment (28), but as is well-documented, their long-term use is associated with side effects, some of them potentially severe (37). Other immunosuppressive medications, such as mercaptopurine, cyclosporine, hydroxychloroquine, mycophenolate mofetil, or abatacept, have been used, with variable success (38-40). Our group of patients had varying use of different immunosuppressive agents, with half of the group having documentation of corticosteroid use at some point and more than one third having received rituximab, but other agents such as mycophenolate mofetil or azathioprine were also used in this population. Additional data on the response of ILD to different agents will be necessary to, if not reaching a consensus, at least define the best available therapies to contain or reverse the progression of lung disease. More knowledge on the genetics and/or pathogenesis for each patient, may allow some ability to tailor these therapies more individually.

That almost one-fifth of the patients discussed here died with a median age of death of 49 years-old is a striking reminder of the shortened life expectation for CVID patients with ILD. This is also highlighted by the 7 patients requiring chronic oxygen and the 5 diagnosed with pulmonary hypertension 
requiring additional therapies. Lung transplantation has been done increasingly for several end-stage lung diseases, and posttransplant survival has improved in the last decades (41). The three patients in our group of 46 with biopsy-proven ILD who underwent lung transplant died. Parenthetically, out of the 637 CVID patients followed in our center, a total of 8 patients have now undergone lung transplant (three of these are part of the 46 patients in this cohort described in Table 5). Only one of these 8 patients submitted to lung transplant is now alive. It remains unclear for which CVID patients with end-stage respiratory disease this would be a viable option.

As our cohort spans almost 50 years of follow-up, only 31 of the 46 patients had a genetic evaluation, but in these, 10 had genes now identified as leading to or associated with this immune defect. In some cases (CTLA4, STAT3), these data may help in suggesting more targeted therapies for ILD (abatacept, or tocilizumab as an anti-IL-6 receptor $\mathrm{mAb}$ ). The increasing use of genetic analysis has helped to better understand and define the CVID syndrome (42-45) and, hopefully, will lead to a better understanding of the pathogenesis and/or suggest new therapies.

\section{DATA AVAILABILITY STATEMENT}

The raw data supporting the conclusions of this article will be made available by the authors, without undue reservation.

\section{REFERENCES}

1. Filion CA, Taylor-Black S, Maglione PJ, Radigan L, Cunningham-Rundles C. Differentiation of common variable immunodeficiency from IgG deficiency. $J$ Allergy Clin Immunol Pract. (2019) 7:1277-84. doi: 10.1016/j.jaip.2018.12.004

2. Chapel H, Cunningham-Rundles C. Update in understanding common variable immunodeficiency disorders (CVIDs) and the management of patients with these conditions. Br J Haematol. (2009) 145:709-27. doi: 10.1111/j.1365-2141.2009.07669.x

3. Bonilla FA, Barlan I, Chapel H, Costa-Carvalho BT, Cunningham-Rundles C, de la Morena MT, et al. International consensus document (ICON): common variable immunodeficiency disorders. J Allergy Clin Immunol Pract. (2016) 4:38-59. doi: 10.1016/j.jaip.2015.07.025

4. Tangye SG, Al-Herz W, Bousfiha A, Chatila T, CunninghamRundles C, Etzioni A, et al. Human inborn errors of immunity: 2019 update on the classification from the international union of immunological societies expert Committee. J Clin Immunol. (2020) 40:24-64. doi: 10.1007/s10875-019-00737-x

5. Lopes JP, Cunningham-Rundles C. The importance of primary immune deficiency registries: the United States immunodeficiency network registry. Immunol Allergy Clin North Am. (2020) 40:385-402. doi: 10.1016/j.iac.2020.03.002

6. Cunningham-Rundles C. Common variable immune deficiency: dissection of the variable. Immunol Rev. (2019) 287:145-61. doi: 10.1111/imr.12728

7. Agarwal S, Cunningham-Rundles C. Autoimmunity in common variable immunodeficiency. Annals Allergy Asthma Immunol. (2019) 123:45460. doi: 10.1016/j.anai.2019.07.014

8. Cunningham-Rundles C. Common variable immune deficiency: case studies. Blood. (2019) 134:1787-95. doi: 10.1182/blood.2019002062

9. Resnick ES, Moshier EL, Godbold JH, Cunningham-Rundles C. Morbidity and mortality in common variable immune deficiency over 4 decades. Blood. (2012) 119:1650-7. doi: 10.1182/blood-2011-09-377945

10. Podjasek JC, Abraham RS. Autoimmune cytopenias in common variable immunodeficiency. Front Immunol. (2012) 3:189. doi: 10.3389/fimmu.2012.00189

\section{ETHICS STATEMENT}

The studies involving human participants were reviewed and approved by Icahn School of Medicine at Mount Sinai Institutional Review Board. Written informed consent to participate in this study was provided by the participants' legal guardian/next of kin.

\section{AUTHOR CONTRIBUTIONS}

All authors participated in the data collection, data analysis, manuscript writing, and manuscript review of the research data here presented.

\section{FUNDING}

This work was partially supported by the National Institutes of Health National Institute of Allergy and Infectious Diseases (AI-061093 and AI-08603) and the David S. Gottesman chair.

\section{ACKNOWLEDGMENTS}

The authors thank Dr. Paul J. Maglione for his extensive collaboration in the research work regarding this patient cohort. They also thank everyone in the CC-R Laboratory.

11. Feuille EJ, Anooshiravani N, Sullivan KE, Fuleihan RL, CunninghamRundles C. Autoimmune cytopenias and associated conditions in CVID: a report From the USIDNET registry. J Clin Immunol. (2018) 38:2834. doi: 10.1007/s10875-017-0456-9

12. Wallis A, Spinks K. The diagnosis and management of interstitial lung diseases. BMJ. (2015) 350:h2072. doi: 10.1136/bmj.h2072

13. Travis WD, Costabel U, Hansell DM, King TE, Lynch DA, Nicholson AG, et al. An official American thoracic society/european respiratory society statement: update of the international multidisciplinary classification of the idiopathic interstitial pneumonias. Am J Respir Crit Care Med. (2013) 188:733-48. doi: 10.1164/rccm.201308-1483ST

14. Harville T. Can we effectively use radiographic imaging and clinical parameters for making an earlier diagnosis of granulomatous interstitial lung disease in patients with common variable immunodeficiency? Annals Allergy Asthma Immunol. (2017) 118:529-30. doi: 10.1016/j.anai.2017.03.003

15. Ho HE, Cunningham-Rundles C. Non-infectious complications of common variable immunodeficiency: updated clinical spectrum, sequelae, and insights to pathogenesis. Front Immunol. (2020) 11:149. doi: 10.3389/fimmu.2020.00149

16. Hanitsch LG, Wittke K, Stittrich AB, Volk HD, Scheibenbogen C. Interstitial lung disease frequently precedes CVID diagnosis. J Clin Immunol. (2019) 39:849-51. doi: 10.1007/s10875-019-00708-2

17. Bates CA, Ellison MC, Lynch DA, Cool CD, Brown KK, Routes JM. Granulomatous-lymphocytic lung disease shortens survival in common variable immunodeficiency. J Allergy Clin Immunol. (2004) 114:41521. doi: 10.1016/j.jaci.2004.05.057

18. Kellner ES, Fuleihan R, Cunningham-Rundles C, Consortium U, Wechsler JB. Cellular defects in CVID patients with chronic lung disease in the USIDNET registry. J Clin Immunol. (2019) 39:569-76. doi: 10.1007/s10875-019-0 0657-w

19. Cunningham-Rundles C, Bodian C. Common variable immunodeficiency: clinical and immunological features of 248 patients. Clin Immunol. (1999) 92:34-48. doi: 10.1006/clim.1999.4725

20. Maglione PJ, Overbey JR, Cunningham-Rundles C. Progression of common variable immunodeficiency interstitial lung disease accompanies distinct 
pulmonary and laboratory findings. J Allergy Clin Immunol Pract. (2015) 3:941-50. doi: 10.1016/j.jaip.2015.07.004

21. Maglione PJ, Overbey JR, Radigan L, Bagiella E, Cunningham-Rundles C. Pulmonary radiologic findings in common variable immunodeficiency: clinical and immunological correlations. Annals Allergy Asthma Immunol. (2014) 113:452-9. doi: 10.1016/j.anai.2014.04.024

22. Park JH, Levinson AI. Granulomatous-lymphocytic interstitial lung disease (GLILD) in common variable immunodeficiency (CVID). Clin Immunol. (2010) 134:97-103. doi: 10.1016/j.clim.2009.10.002

23. Mannina A, Chung JH, Swigris JJ, Solomon JJ, Huie TJ, Yunt ZX, et al. Clinical predictors of a diagnosis of common variable immunodeficiencyrelated granulomatous-lymphocytic interstitial lung disease. Ann Am Thorac Soc. (2016) 13:1042-9. doi: 10.1513/AnnalsATS.201511-728OC

24. Weinberger T, Fuleihan R, Cunningham-Rundles C, Maglione PJ. Factors beyond lack of antibody govern pulmonary complications in primary antibody deficiency. J Clin Immunol. (2019) 39:4407. doi: 10.1007/s10875-019-00640-5

25. Hurst JR, Verma N, Lowe D, Baxendale HE, Jolles S, Kelleher P, et al. British lung foundation/United Kingdom primary immunodeficiency network consensus statement on the definition, diagnosis, and management of granulomatous-lymphocytic interstitial lung disease in common variable immunodeficiency disorders. J Allergy Clin Immunol Pract. (2017) 5:93845. doi: 10.1016/j.jaip.2017.01.021

26. Tessarin G, Bondioni MP, Rossi S, Palumbo L, Soresina A, Badolato R, et al. Rituximab as a single agent for granulomatous lymphocytic interstitial lung disease in common variable immune deficiency. J Investig Allergol Clin Immunol. (2019) 29:470-1. doi: 10.18176/jiaci.0450

27. Chase NM, Verbsky JW, Hintermeyer MK, Waukau JK, Tomita-Mitchell A, Casper JT, et al. Use of combination chemotherapy for treatment of granulomatous and lymphocytic interstitial lung disease (GLILD) in patients with common variable immunodeficiency (CVID). J Clin Immunol. (2013) 33:30-9. doi: 10.1007/s10875-012-9755-3

28. Long $\mathrm{K}$, Danoff SK. Interstitial lung disease in polymyositis and dermatomyositis. Clin Chest Med. (2019) 40:56172. doi: 10.1016/j.ccm.2019.05.004

29. Rao N, Mackinnon AC, Routes JM. Granulomatous and lymphocytic interstitial lung disease: a spectrum of pulmonary histopathologic lesions in common variable immunodeficiency-histologic and immunohistochemical analyses of 16 cases. Hum Pathol. (2015) 46:1306-14. doi: 10.1016/j.humpath.2015.05.011

30. Patel S, Anzilotti C, Lucas M, Moore N, Chapel H. Interstitial lung disease in patients with common variable immunodeficiency disorders: several different pathologies? Clin Exp Immunol. (2019) 198:212-23. doi: 10.1111/cei. 13343

31. Maarschalk-Ellerbroek LJ, de Jong PA, van Montfrans JM, Lammers JW, Bloem AC, Hoepelman AI, et al. CT screening for pulmonary pathology in common variable immunodeficiency disorders and the correlation with clinical and immunological parameters. J Clin Immunol. (2014) 34:64254. doi: 10.1007/s10875-014-0068-6

32. Maglione PJ, Gyimesi G, Cols M, Radigan L, Ko HM, Weinberger $\mathrm{T}$, et al. BAFF-driven $\mathrm{B}$ cell hyperplasia underlies lung disease in common variable immunodeficiency. JCI Insight. (2019) 4:e122728. doi: 10.1172/jci.insight. 122728

33. Hartono S, Motosue MS, Khan S, Rodriguez V, Iyer VN, Divekar R, et al. Predictors of granulomatous lymphocytic interstitial lung disease in common variable immunodeficiency. Annals Allergy Asthma Immunol. (2017) 118:61420. doi: 10.1016/j.anai.2017.01.004

34. Ardeniz O, Cunningham-Rundles C. Granulomatous disease in common variable immunodeficiency. Clin Immunol. (2009) 133:198-207. doi: 10.1016/j.clim.2009.05.001

35. Ng J, Wright K, Alvarez M, Hunninghake GM, Wesemann DR. Rituximab monotherapy for common variable immune deficiency-associated granulomatous-lymphocytic interstitial lung disease. Chest. (2019) 155:e117-21. doi: 10.1016/j.chest.2019.01.034

36. Cereser L, De Carli R, Girometti R, De Pellegrin A, Reccardini F, Frossi $\mathrm{B}$, et al. Efficacy of rituximab as a single-agent therapy for the treatment of granulomatous and lymphocytic interstitial lung disease in patients with common variable immunodeficiency. J Allergy Clin Immunol Pract. (2019) 7:1055-7.e2. doi: 10.1016/j.jaip.2018.10.041

37. Ericson-Neilsen W, Kaye AD. Steroids: pharmacology, complications, and practice delivery issues. Ochsner J. (2014) 14:203-7.

38. Volkmann ER, Tashkin DP, Li N, Roth MD, Khanna D, Hoffmann-Vold AM, et al. Mycophenolate mofetil versus placebo for systemic sclerosis-related interstitial lung disease: an analysis of scleroderma lung studies I and II. Arthritis Rheumatol. (2017) 69:1451-60. doi: 10.1002/art.40114

39. Huapaya JA, Silhan L, Pinal-Fernandez I, Casal-Dominguez M, Johnson C, Albayda J, et al. Long-term treatment with azathioprine and mycophenolate mofetil for myositis-related interstitial lung disease. Chest. (2019) 156:896906. doi: 10.1016/j.chest.2019.05.023

40. Mecoli CA, Christopher-Stine L. Management of interstitial lung disease in patients with myositis specific autoantibodies. Curr Rheumatol Rep. (2018) 20:27. doi: 10.1007/s11926-018-0731-7

41. Thabut G, Mal H. Outcomes after lung transplantation. J Thorac Dis. (2017) 9:2684-91. doi: 10.21037/jtd.2017.07.85

42. Maffucci P, Filion CA, Boisson B, Itan Y, Shang L, Casanova $\mathrm{JL}$, et al. Genetic diagnosis using whole exome sequencing in common variable immunodeficiency. Front Immunol. (2016) 7:220. doi: 10.3389/fimmu.2016.00220

43. Maffucci P, Bigio B, Rapaport F, Cobat A, Borghesi A, Lopez M, et al. Blacklisting variants common in private cohorts but not in public databases optimizes human exome analysis. Proc Natl Acad Sci USA. (2019) 116:9509. doi: $10.1073 /$ pnas. 1808403116

44. Resnick ES, Cunningham-Rundles C. The many faces of the clinical picture of common variable immune deficiency. Curr Opin Allergy Clin Immunol. (2012) 12:595-601. doi: 10.1097/ACI.0b013e32835914b9

45. Abolhassani H, Hammarstrom L, Cunningham-Rundles C. Current genetic landscape in common variable immune deficiency. Blood. (2020) 135:65667. doi: 10.1182/blood.2019000929

Conflict of Interest: The authors declare that research was conducted in the absence of any commercial or financial relationships that could be construed as a potential conflict of interest.

Copyright (c) 2021 Lopes, Ho and Cunningham-Rundles. This is an open-access article distributed under the terms of the Creative Commons Attribution License (CC $B Y)$. The use, distribution or reproduction in other forums is permitted, provided the original author(s) and the copyright owner(s) are credited and that the original publication in this journal is cited, in accordance with accepted academic practice. No use, distribution or reproduction is permitted which does not comply with these terms. 